\title{
EXPERIMENTAL INVESTIGATION ON VOLUMETRIC PROPERTIES OF BITUMINUOUS CONCRETE MIXES WITH HOT MIX ASPHALT AND WARM MIX ASPHALT TECHNOLOGY
}

\author{
Aditya Tantry ${ }^{\# 1}$, Archana G M ${ }^{\# 2}$, G M Shankarmurthy ${ }^{\# 3}$, Prashanth Wuruli ${ }^{\# 4}$, Praveen $\mathrm{R}^{\# 5}$ \\ \# Department of Civil Engineering, Alva's Institute of Engineering and Technology \\ Shobhavana Campus, Mijar, Moodabidri, Karnataka, India-574225 \\ 1 aditya.tantry001@gmail.com, \\ 2archanagm96@gmail.com, ${ }^{3}$ shankargm2014@gmail.com \\ ${ }^{4}$ prashanth.wuruli@gmail.com, ${ }^{5}$ ___praveen@outlook.com
}

\begin{abstract}
Hot Mix Asphalt (HMA) is an old technology, which involves in production, laying and compaction at a higher temperature, which emits more pollution and increases the energy requirement. The Warm Mix Asphalt (WMA), which is produced, laid and compacted in temperature, which is much lower than conventional mix. The WMA is produced by adding chemical additives to the bitumen during mixing to obtain same performance at lower temperature. The strength, durability and workability of asphalt paving mixtures have changed significantly due to the use of additives. Warm Mix Asphalt (WMA) is an example of such additives, which lowers the temperature of the asphalt mix between $20^{\circ} \mathrm{C}$ to $40^{\circ} \mathrm{C}$ as compared to conventional HMA. A research study was conducted to evaluate the Dense Bituminous concrete Mix with additives such as Sasobit, Evotherm, Rediset and Zycotherm. These additives were added as per the company specified optimum dosage to the Dense Bituminous concrete Mix(DBM)and the specimens with varying binder content of $4.50 \%, 5.50 \%$ and $6.50 \%$ were prepared. These specimens were tested for their volumetric properties by using Marshall Stability test such as Marshall Stability, Flow value, Air voids percentage, Voids filled with bitumen, Marshallquotient, the test results were obtained and correspondingly the results are analysed through graphs. According to the comparative analysis of DBM with different additives, the warm mix asphalt with Sasobit (WMA-S) of dosage $3 \%$ at Optimum Bitumen Content of $5.45 \%$ was found to be economical and satisfied all the aspects and represents the better performance.
\end{abstract}

Keyword - WMA1, HMA2, DBM3, Zycotherm4, Evotherm5, Rediset6, Sasobit7.

\section{INTRODUCTION}

In development of the country and economic growth, construction sector plays a key role in it. In India, construction sector stands as the second largest economic activity while agriculture is the first largest economic activity. Currently, the roads are of Flexible pavement which is surfaced with Hot Mix Asphalt (HMA). HMA is recognised as the high quality engineered paved material, since 130 years. The production and placement of HMA is modernized gradually during these periods. The production of HMA is from the combination of well graded aggregates and bitumen mixed together under high temperature of around $150^{\circ} \mathrm{C}$ to $170^{\circ} \mathrm{C}$, through Batch Mix plant or Drum Mix plant. The main concern regarding production of HMA is, it requires large amount of energy with the release of gases to the environment. This created asphalt industry to look for an alternate material or technology which could reduce those facts. Warm Mix Asphalt (WMA) is one of those technologies, originated in Europe. WMA allows in sufficient reduction in mixing and compaction temperature of the asphalt mixes by lowering the viscosity of the asphalt binders. WMA can be considered as the modified mixture of HMA which is produced, placed and compacted at $10^{\circ} \mathrm{C}$ to $40^{\circ} \mathrm{C}$ lower than the conventional method (HMA). This technique has been proved that, it provide various benefits including reduction in fuel consumption and emission, extension in construction season, improved compaction and liberal in construction practices. Due to the different mechanism in WMA preparation techniques, the physical and chemical properties can be altered. This results in various short term and long term behaviour. To evaluate this laboratory test of asphalt mixture with regards to various other pavement distress by using various other warm mix additives like Evotherm, Sasobit, Zycotherm and Redisetwith variation in temperature of mixing, compaction and laying. It is conduced based on Marshall Method of bitumen mix design. The Optimum Bitumen Content (OBC) of HMA \&WMA is determined. Due to the different mechanism in WMA preparation techniques, the physical and chemical properties can be altered. 


\section{MATERIAL AND METHODOLOGY}

Research work has been carried out on bituminous mixes with addition of chemical additives in bitumen with different dosage. However, the present work is carried out to study the various different properties of bituminous concrete mix with chemical additives when aggregate are heated. At present an attempt is made to investigate the volumetric properties of Dense Bituminous Macadam (DBM) of grade I, having layer thickness 75-100 mm, and mixes for HMA \& WMA using additives like Sasobit, Radiset, Evotherm, and Zycotherm.

\section{A. Types of material selected}

\section{- Bitumen}

In the present investigation unmodified bitumen of grade VG30 was used as the mean highest temperature in the investigated region is around $30^{\circ} \mathrm{C}$. The Bitumen used in this study was tested in laboratory for various physical properties like Penetration, ductility, Softening Point, Specific Gravity and Flash \& Fire point were evaluated and the results are tabulated in following Tables3.1.

Table 3.1 Physical Properties of VG30 grade Bitumen

\begin{tabular}{|l|l|c|c|}
\hline PROPERTY TESTED & TEST METHOD & RESULTS & SPECIFICATION \\
\hline Penetration & IS $1203-1978$ & $67 * 1 / 10 \mathrm{~mm}$ & $60-70 * 1 / 10 \mathrm{~mm}$ \\
\hline Softening point, ${ }^{0} \mathrm{C}$ & IS $1205-1978$ & $58^{0} \mathrm{C}$ & $30{ }^{\circ} \mathrm{C}-157^{\circ} \mathrm{C}$ \\
\hline Ductility at $27^{\circ} \mathrm{C}$ & IS $1208-1978$ & $86 \mathrm{~cm}$ & $70-100 \mathrm{~cm}$ \\
\hline Specific Gravity & IS $1202-1978$ & 1.016 & $0.97-1.02$ \\
\hline Flash point, ${ }^{0} \mathrm{C}$ & IS $1209-1978$ & $226^{0} \mathrm{C}$ & $210^{0} \mathrm{C}$ \\
\hline Fire point, ${ }^{\circ} \mathrm{C}$ & IS $1209-1978$ & $247^{0} \mathrm{C}$ & - \\
\hline
\end{tabular}

- Aggregate

Aggregate having sufficient strength, hardness, toughness, specific gravity and shape are chosen from the quarry at Edapadavu rural,Mangalore taluk. The properties of aggregates used in the present study are tabulated in Table 3.2

Table 3.2 Properties of aggregate

\begin{tabular}{|l|l|c|c|}
\hline \multicolumn{1}{|c|}{ PROPERTY TESTED } & TEST METHOD & RESULTS & SPECIFICATION \\
\hline Aggregate Impact Value & IS 2386(part IV) & $26.68 \%$ & $30 \%$ \\
\hline Los Angeles Abrasion Value & IS 2386(part IV) & $43.04 \%$ & $50 \%$ \\
\hline Aggregate Crushing Value & IS 2386(part IV) & $25.89 \%$ & $40 \%$ \\
\hline Specific Gravity & IS 2386(part III) & 2.51 & $2.5-3.5$ \\
\hline Flakiness \& Elongation Index & IS 2386(part I) & $26.98 \%$ & $30 \%$ \\
\hline
\end{tabular}

- Chemical Admixtures

Table 3.3 Properties of chemical admixtures

\begin{tabular}{|c|c|c|c|c|c|}
\hline ADMIXTURE & TYPE & FORM & COLOUR & $\begin{array}{c}\text { DOSAGE BY } \\
\text { WEIGHT OF } \\
\text { BITUMEN }\end{array}$ & $\begin{array}{c}\text { OPTIMUM } \\
\text { DOSAGE } \\
\text { PREFERRED }\end{array}$ \\
\hline Sasobit & Organic & Crystalline or wax & Milky white & $3 \%$ & $3 \%$ \\
\hline Rediset & Chemical & Liquid & Yellowish Gold & $0.5 \%$ & $0.5 \%$ \\
\hline Evotherm & Chemical & Liquid & Brownish Black & 0.25 to $0.50 \%$ & $0.375 \%$ \\
\hline Zycotherm & Chemical & Liquid & Colourless & $0.1 \%$ & $0.1 \%$ \\
\hline
\end{tabular}

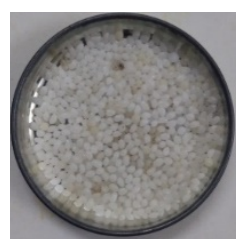

Sasobit

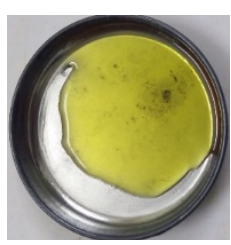

Redsiset

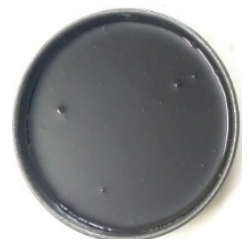

Evotherm

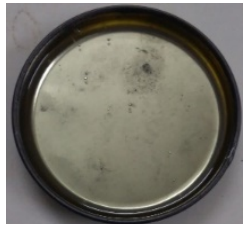

Zycotherm

Fig 1: Types of Chemical admixture 


\section{B. Aggregate gradation adopted}

Selected aggregate gradation satisfied the requirement of the Ministry of Road Transport and Highway (MoRT\&H, 2013) specification. For present investigation mid-gradation were considered for base and surface course for Grading-I of DBM having layer thickness 75-100 mm. The same details are represented in the following Table 3.3

Table 3.3 Aggregate gradation

\begin{tabular}{|c|c|c|c|}
\hline NOMINAL AGGREGATE SIZE & \multicolumn{3}{|c|}{$37.5 \mathrm{~mm}$} \\
\hline LAYER THICKNESS & \multicolumn{3}{|c|}{ 75-100 mm } \\
\hline \multirow[t]{2}{*}{ IS SIEVE(mm) } & \multicolumn{3}{|c|}{$\begin{array}{l}\text { CUMULATIVE \% BY WEIGHT OF TOTAL } \\
\text { AGGREGATE PASSING }\end{array}$} \\
\hline & $\begin{array}{l}\text { Specified } \\
\text { limits }\end{array}$ & $\begin{array}{l}\text { Adopted } \\
\text { gradation }\end{array}$ & $\begin{array}{l}\text { Actual weight } \\
\text { in grams }\end{array}$ \\
\hline 37.5 & 100 & 100 & 36 \\
\hline 26.5 & $95-100$ & 97.5 & 240 \\
\hline 19 & - & - & - \\
\hline 13.2 & $55-75$ & 65 & 156 \\
\hline 9.5 & - & - & - \\
\hline 4.75 & $38-54$ & 46 & 228 \\
\hline 2.36 & $28-42$ & 35 & 132 \\
\hline 1.18 & - & - & - \\
\hline 0.6 & - & - & - \\
\hline 0.3 & $7-21$ & 14 & 252 \\
\hline 0.15 & - & - & - \\
\hline 0.075 & $2-8$ & 5 & 108 \\
\hline Bitumen content \% by mass of total mix & $4 \% \min$ & - & - \\
\hline
\end{tabular}

\section{FLOW CHART OF METHODOLOGY}

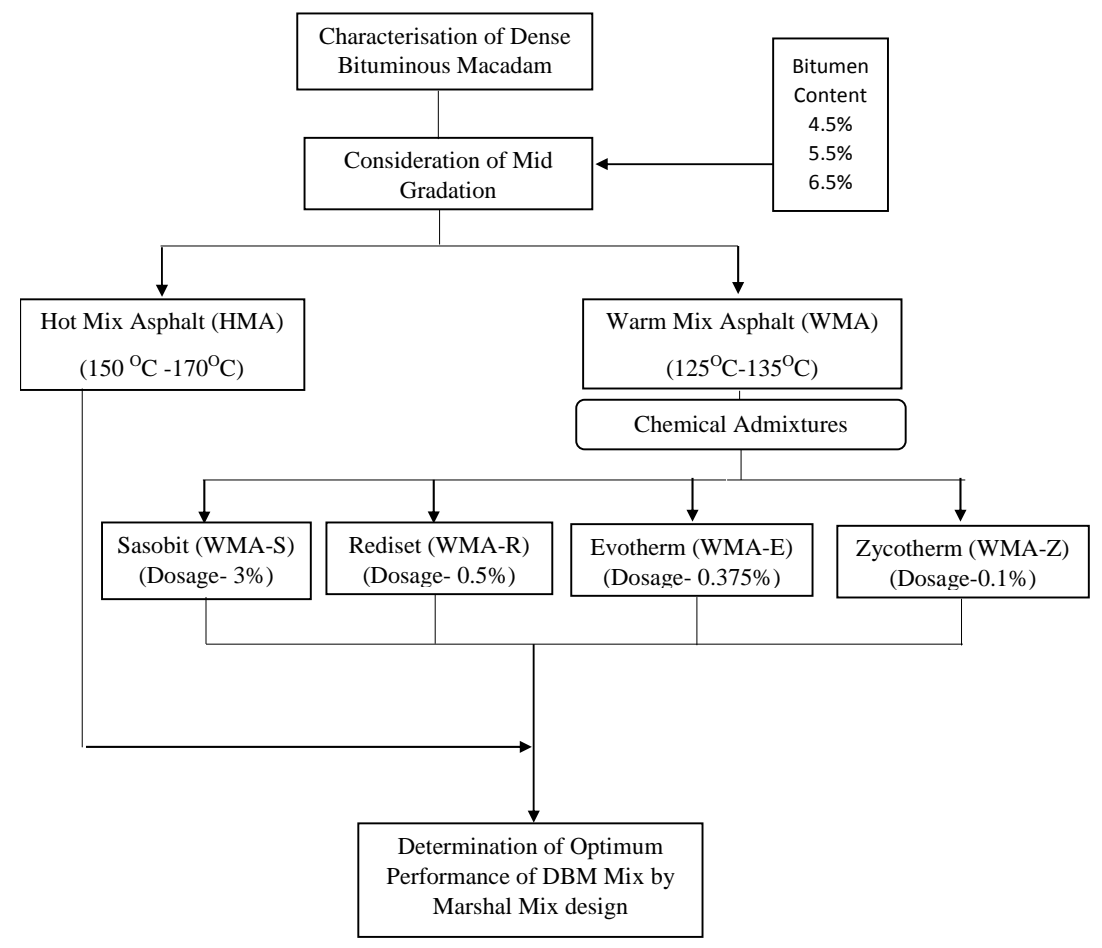

Fig 2.5 Flow chart of the experimental methodology 


\section{RESULTSAND DISCUSSION}

In this present study mixes (Grade-I) are prepared by adding bitumen to the mix by weight of aggregates and the Chemical additives like Sasobit, Rediset, Evotherm and Zycotherm added into optimum dosage by weight of bitumen (VG30). Marshall Mix design is done for different percentage of bitumen mix. The samples are tested for their properties and respectively their marshal stability, flow value, bulk specific gravity, air voids percentage, voids filled with mineral aggregate, voids filled with bitumen and Marshallquotient are found. These properties are represented in the form of graphs and are compared among each other. The optimum bitumen content for Dense Bituminous Macadam of grade-I was found by obtaining the average of $4 \%$ air voids, maximum bulk specific gravity and maximum Marshall Stability. The respective properties like Marshall stability, flow value, bulk specific gravity, air voids percentage, voids filled with mineral aggregate(VMA), voids filled with bitumen(VFB) and marshal quotient obtained at these optimum bitumen content are compared with each other to determine the best mix.

\section{A. Bituminous mix of Viscosity Graded bitumen}

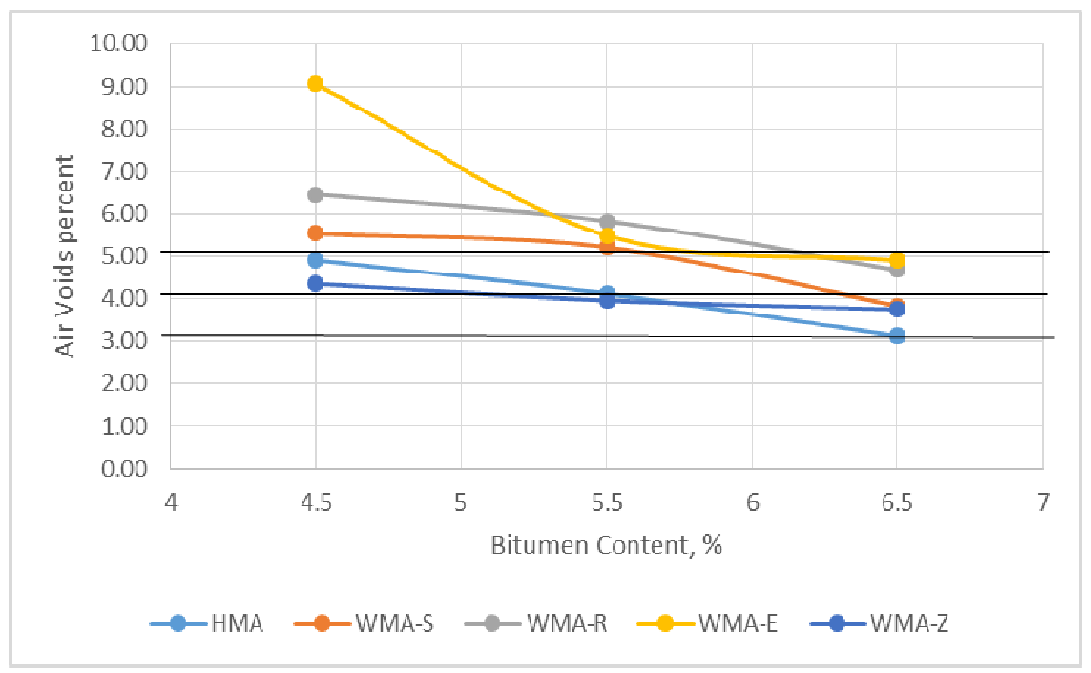

Fig 3.1: Bitumen content v/s Air Voids Percent

Figure 3.1 shows the variation in air voids with respect to the incremental bitumen content at $1 \%$ incremental rate with HMA and WMA mixes for DBM grade-I of layer thickness 75-100 mm. According to MoRT\&H specification, air voids should be $3 \%$ to $5 \%$ of bituminous mixes. In the present investigation for $3 \%$ air voids the bitumen content was found to be $6.63 \%$ for HMA mix. At the same time for $4 \%$ air voids, the bitumen content was found to be 5.62\% for HMA mix, 6.37\% for WMA-S, and 5.57\% for WMA-Z. In the upper limit at $5 \%$ air voids the bitumen content for WMA-S was found to be 5.65\%, and for WMA-E was 6.34\%. From the study it was found that WMA-Z is succeed to perform with same compaction as of HMA mix, significantly the compaction effect at $5.50 \%$ bitumen content found to be same for both mixes. By this it was found that rearrangement of particle succeed in WMA-Z at 5.50\% bitumen content as same of HMA mix.

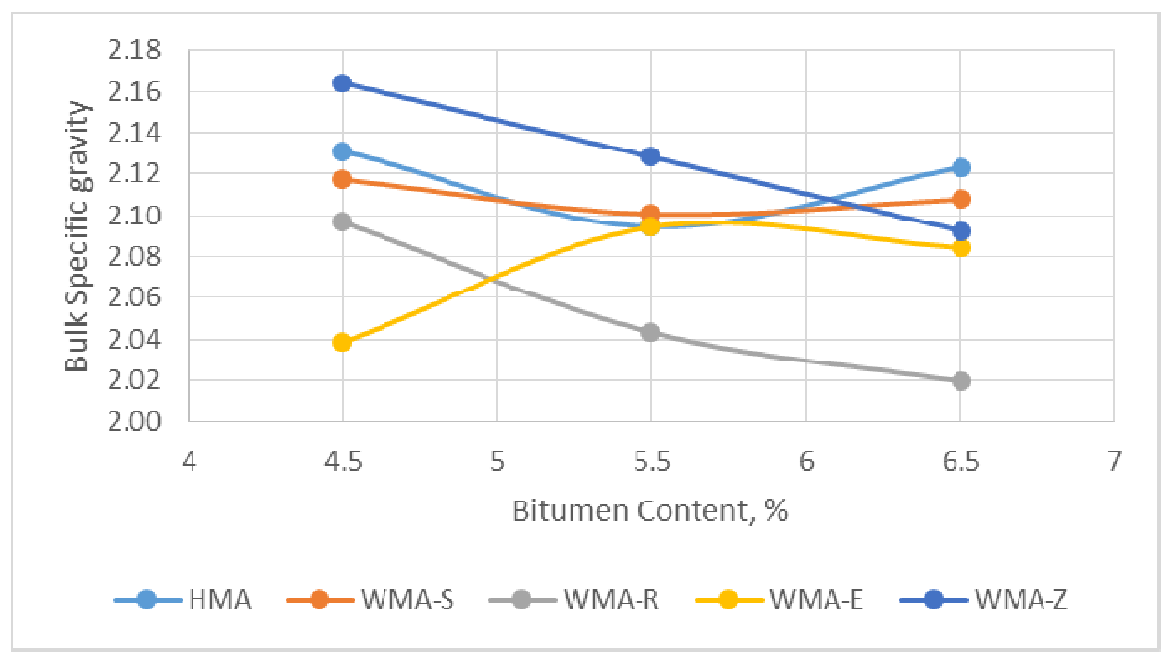

Fig 3.2: Bitumen content v/s Bulk Specific Gravity 
Figure 3.2 shows the variation in Bulk Specific Gravity for incremental bitumen content with HMA and WMA mixes for DBM grade-I of layer thickness 75-100 mm. Bulk Specific Gravity are within the desired range. At the bitumen content $4.50 \%$ Bulk specific gravity for WMA-Z is $1.4 \%$ higher than HMA which indicates the higher rate of compaction, at the same bitumen content bulk specific gravity of WMA-E is $4.41 \%$ lower than HMA which indicates the lower rate of compaction. Even at $5.50 \%$ bitumen content the bulk specific gravity of WMA-Z is $1.91 \%$ which is higher than HMA and WMA-R has $2.45 \%$ lower bulk specific gravity than that ofHMA. But at $6.50 \%$ bitumen content, the bulk specific gravity of HMA is higher and WMA-S has $0.47 \%$ lesser value than that of HMA, also at the same bitumen content WMA-R has the least Bulk specific gravity which is $4.71 \%$ lesser than that of HMA. Considering the overall behaviour, WMA-Z shows the higher bulk specific gravity at the bitumen content of $4.50 \%$ and $5.50 \%$ but the bulk specific gravity gets reduced as the bitumen content increases. At 6.50\% bitumen content WMA-S shows better bulk specific gravity.

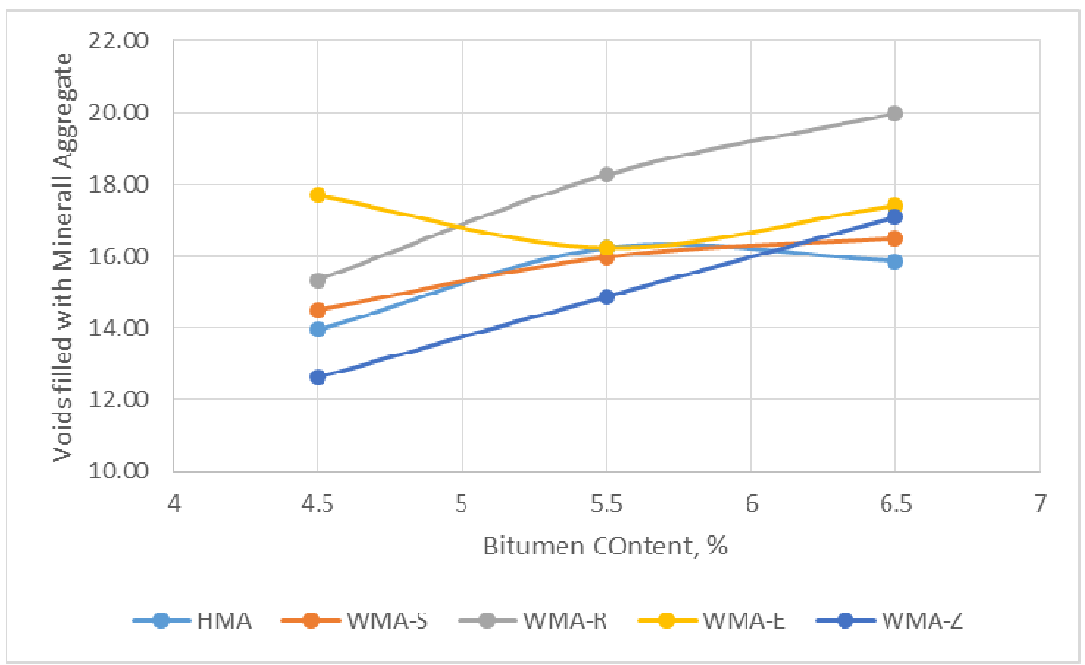

Fig 3.3: Bitumen content v/s Voids filled with Mineral aggregate

Figure 3.3 shows the variation in Voids filled with Mineral Aggregate for incremental bitumen, with HMA and WMA mixes for DBM grade-I of layer thickness 75-100 mm. All the DBM mixes for VMA have desired range as per MoRT\&H. At the bitumen content of 4.50\%, WMA-E has 26.88\% higher VMA than HMA, considering the same WMA-Z has 9.53\% lower VMA value than HMA. At the bitumen content of 5.50\%, WMA-R has $12.63 \%$ higher VMA than HMA and the VMA of WMA-Z is $8.31 \%$ lesser than HMA at the same bitumen content. But at the bitumen content of 6.50\%, VMA of all WMA mixes are higher than that of VMA of HMA, WMA-R is said to have the highest value of VMA at the same bitumen content which is $25.96 \%$ higher than HMA.WMA-Z shows the better compaction at $4.50 \%$ and $5.50 \%$ bitumen content, but the compaction efficiency decreases at the higher temperature. Considering all the mixes, WMA-S shows the better compaction at all bitumen contents and it behaves almost same as the HMA mix. Hence it can be used in replacement to HMA.

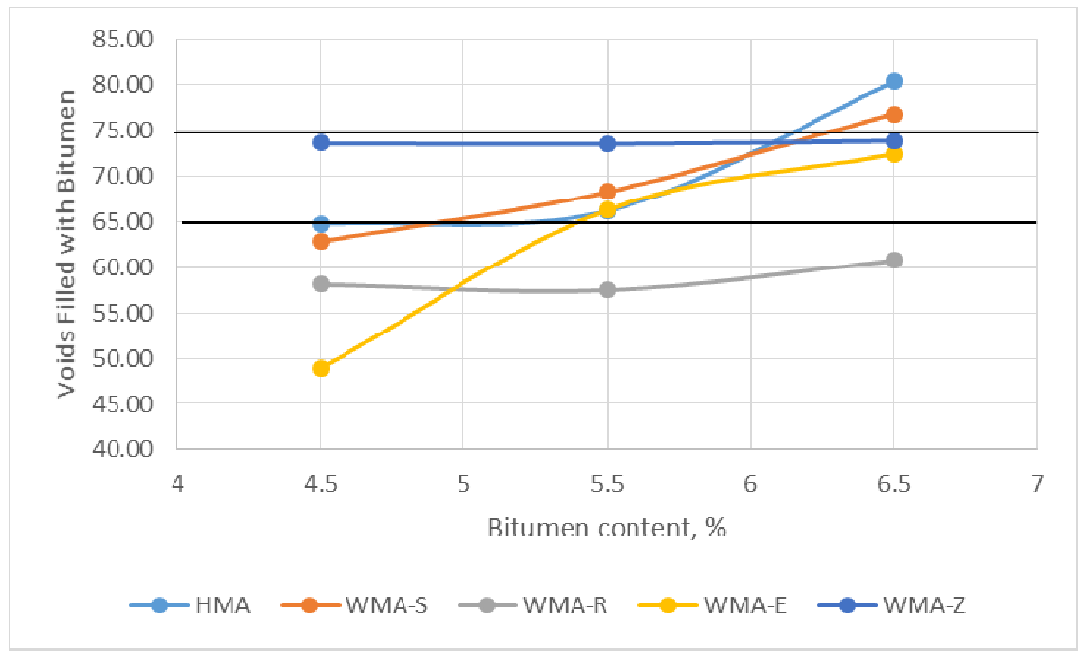

Fig 3.4: Bitumen content v/s Voids Filled with Bitumen 
Figure 3.4 shows the variation in Voids filled with bitumen for varying bitumen content with HMA and WMA mixes for DBM grade-I of layer thickness $75-100 \mathrm{~mm}$. It was found that, at 4.50\% bitumen content HMA and WMA-Z had the desired VFB and at the same bitumen content WMA-Z shows the higher VFB of 73.62\% which is $13.64 \%$ greater than HMA. At 5.50\% bitumen content, HMA, WMA-S, WMA-Z and WMA-E had VFB within the desired range and at the same point WMA-Z possess higher VFB which is $11.10 \%$ higher than HMA. At the bitumen content of 6.50\%, WMA-Z and WMA-E had their VMA within the desired range but VFB of HMA is more than the desired range. From overall observation, it was found that HMA has failed to satisfy desired range of VFB at $6.50 \%$. But significantly it can be state that WMA-Z satisfies the required VFB at all bitumen content. Hence, WMA-Z can be the replacement to HMA at higher bitumen content.

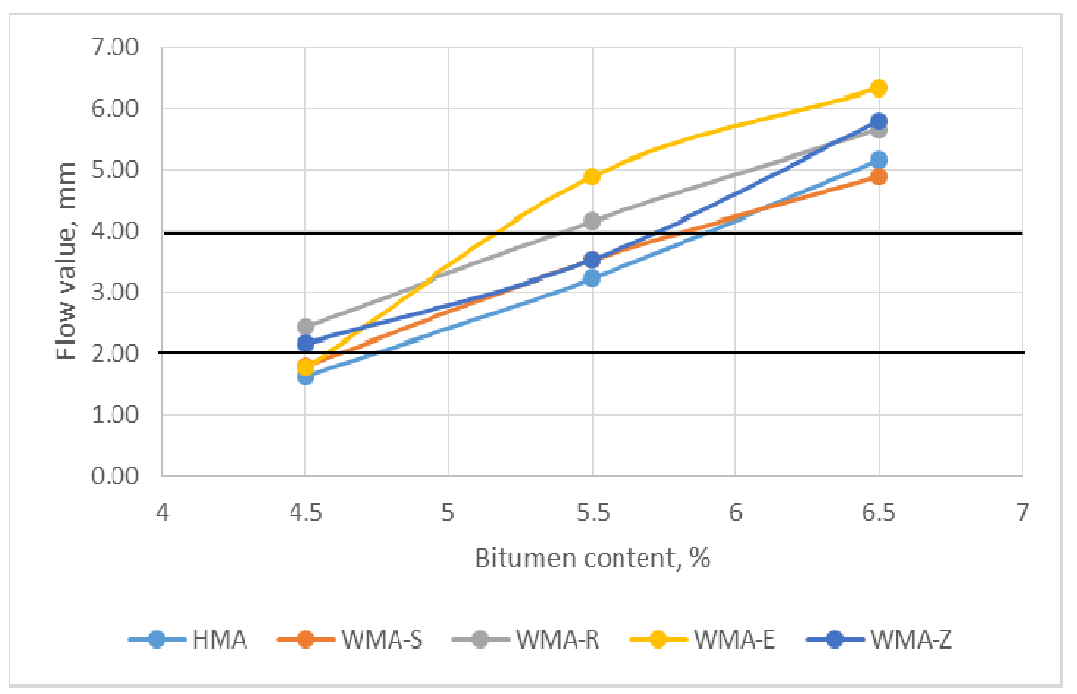

Fig 3.5: Bitumen content v/s Flow value

Figure 3.5 shows the variation in flow value for incremental bitumen content with HMA and WMA mixes for DBM grade-I of layer thickness 75-100 mm. It can be stated that usage of additives results in the increase of flow value as compared to HMA, hence this leads to a drawback which leads to Segregation. Even the flow value should not be lesser than the desired range as it reduces the workability. At $4.50 \%$ bitumen content, the flow values of WMA-R and WMA-Z are within the specified limit as per MoRT\&H and flow value of HMA 1.63 which is lesser than desired value. At 5.50\% bitumen content the flow value of HMA, WMA-Z and WMA$\mathrm{S}$ are within the desired range. At the bitumen content of $6.50 \%$ the flow values for all the mixes are exceeding the desired limit, WMA-S is said to lower among them and has the value of 4.90. From the overall observation, significantly it can be stated that WMA-E is not preferred as it does not have the required flow property and has the highest flow value of 4.90 and 6.33 at $5.50 \%$ and $6.50 \%$ bitumen content. As a comparison of HMA and WMA mixes the flow value of WMA-S is within the specified range, except $6.50 \%$ bitumen content, hence it is preferable.

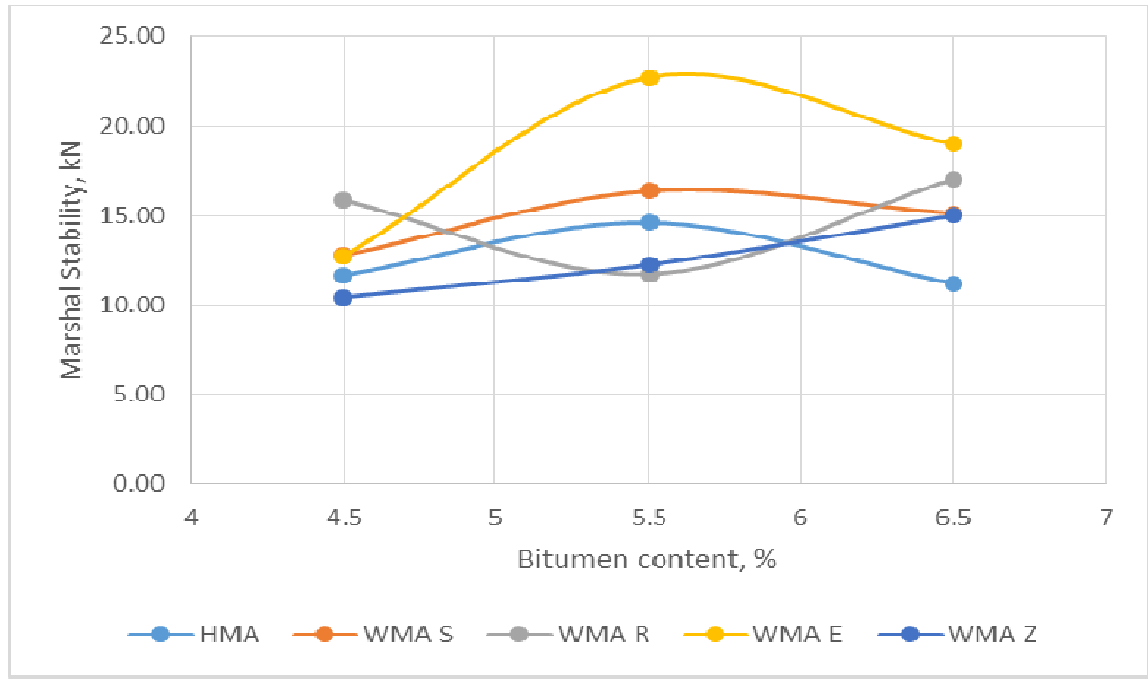

Fig 3.6: Bitumen content v/s Marshal Stability 
Figure 3.6 shows the variation in Marshal Stability for incremental bitumen content with HMA and WMA mixes for DBM grade-I of layer thickness 75-100 mm. According to MoRT\&H specification, all the mixes of HMA and WMA satisfy the minimum stability criteria of $9 \mathrm{kN}$. In accordance with the figure, for binder content $4.50 \%$, HMA had stability of $11.65 \mathrm{kN}$, at the same WMA-R had maximum stability which is $24.19 \%$ greater than WMA-S, also WMA-Z had minimum stability which $10.38 \%$ lesser than the stability of HMA. For binder content $5.50 \%$, HMA has stability of $14.60 \mathrm{kN}$, at the same WMA-E has maximum stability which is $38.79 \%$ greater than that of WMA-S and WMA-R has minimum stability of about $19.70 \%$ less than HMA. Similarly for binder content of $6.50 \%$, HMA has stability of $11.19 \mathrm{kN}$ which is least compared to all mixes and WMA-E has the highest stability which is $69.70 \%$ higher than HMA. From the overall observation, it can be said that WMA$\mathrm{E}$ is preferred as it has the higher stability at $5.50 \%$ and $6.50 \%$ bitumen content. Even though WMA-Z has the minimum stability, but it is lesser when compared to other mixes and hence it is least preferred.

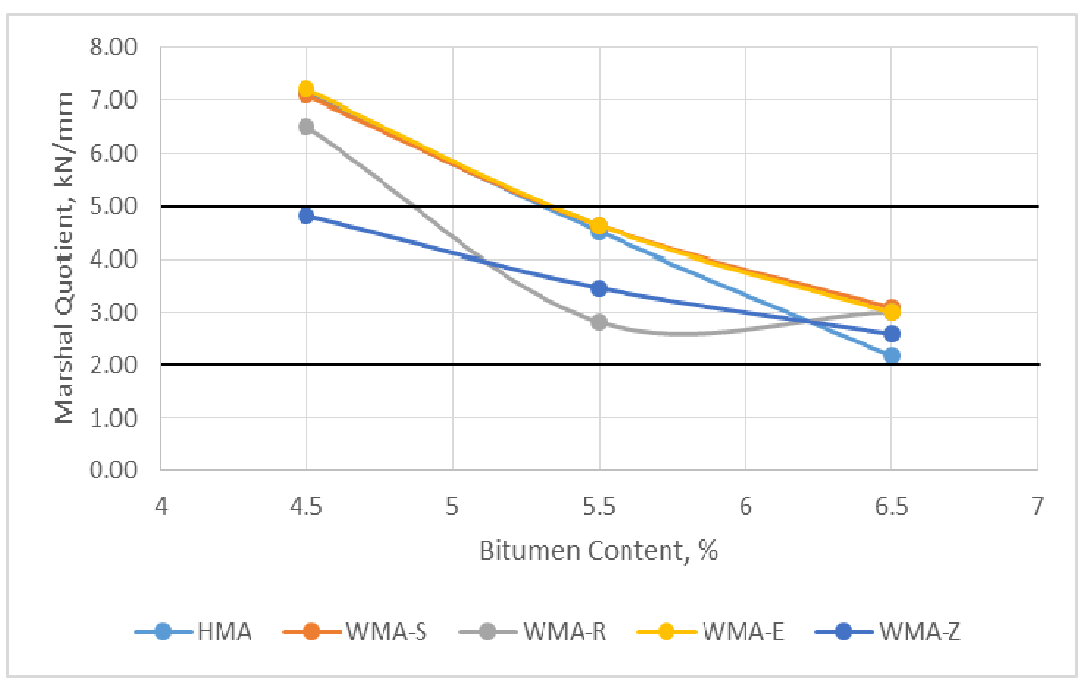

Fig 3.7: Bitumen content v/s Marshal Quotient

Figure 3.7 shows the variation in Marshal Quotient for incremental bitumen content with HMA and WMA mixes for DBM grade-I of layer thickness $75-100 \mathrm{~mm}$. At bitumen content $5.50 \%$ and $6.50 \%$ of HMA and WMA mixes, have marshal quotient found within the desired range as per MoRT\&H specification. For all the binder contents, WMA-Z shows the best Marshal quotient behaviour and also it is within the specified limit throughout.

\section{B. Evaluation of DBM mixes at Optimum Bitumen Content}

In the present investigation Optimum Bitumen Content was determined with respect to $4 \%$ air voids, maximum bulk specific gravity and maximum marshal stability for HMA and WMA mixes were found and test were also conducted to evaluate volumetric properties.

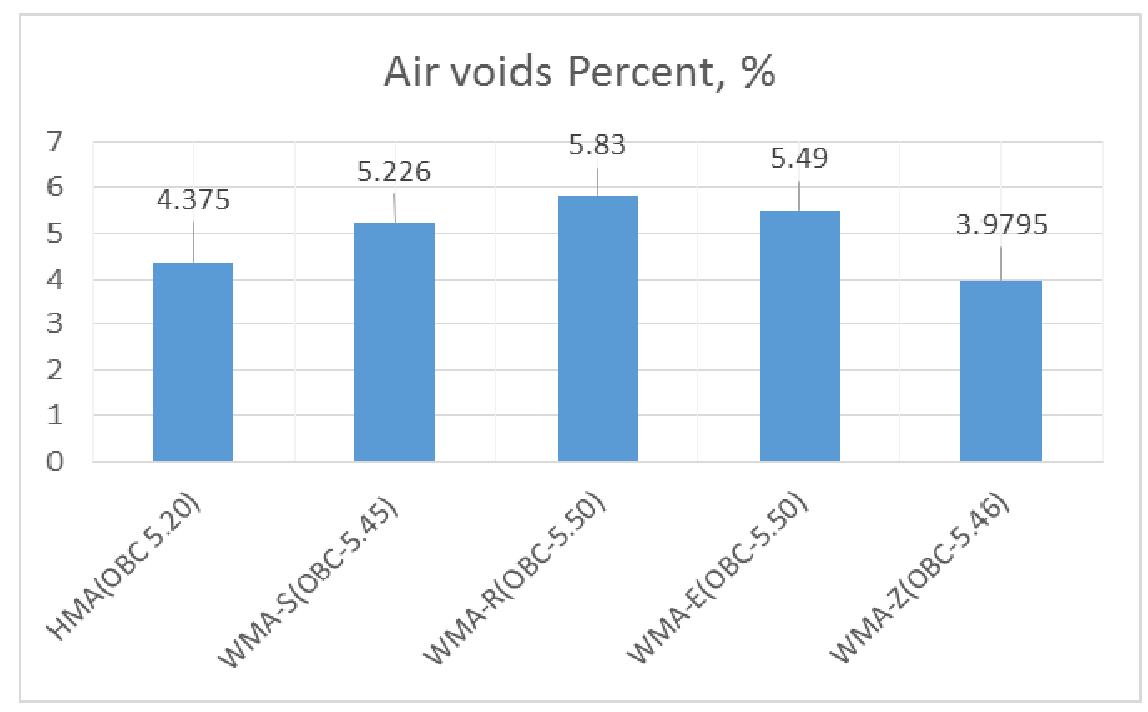

Fig 3.8 (a) Air Voids percent for OBC 
From Figure 3.8 (a), the observation shows that WMA-Z with OBC 5.46\% has the satisfactory value of air voids percentage and also better performance at lesser bitumen content. It is noticed that WMA-R and WMA-E are even though having same OBC, the percentage of air voids in WMA-E is $6.19 \%$ lesser than WMA-R which leads in better packing capacity and compaction. Hence WMA-E is better than WMA-R.

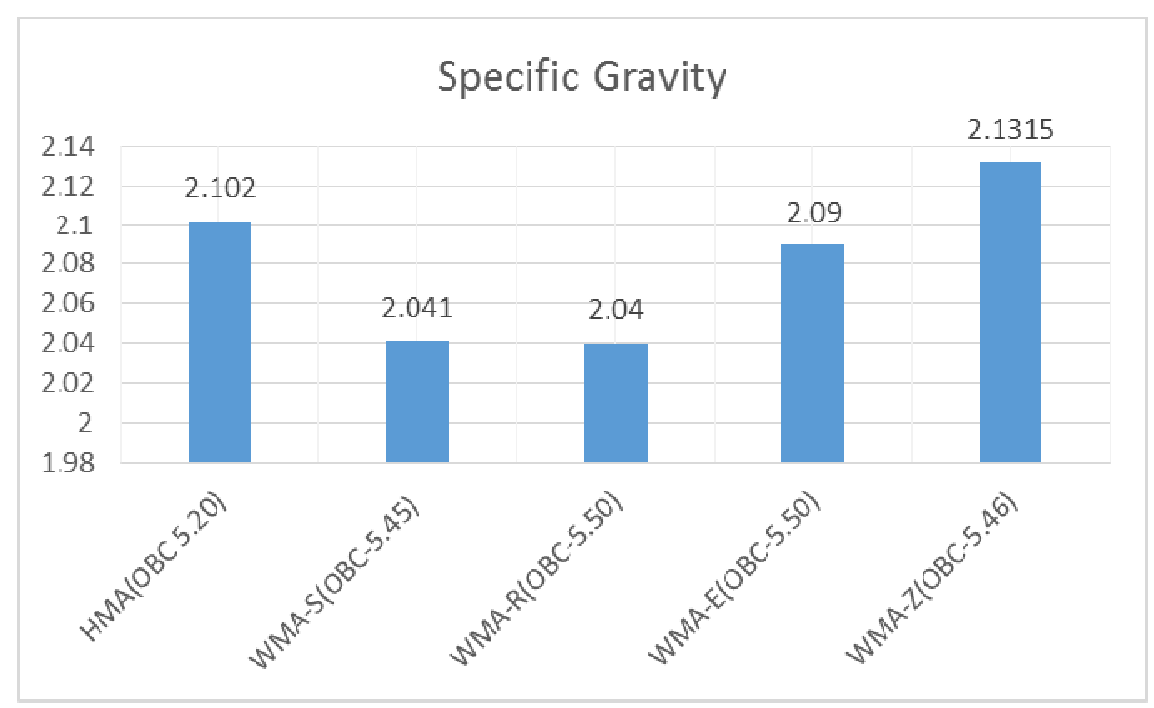

Fig 3.8 (b) Bulk specific gravity for OBC

The specific gravity at OBC are represented in the figure 3.8(b).It was found that WMA-Z with OBC 5.46\% has got the higher value of specific gravity which is $1.40 \%$ greater than HMA. From overall mixes, WMA-Z is preferred as denser mix. Considering WMA-R and WMA-E which are having the same OBC, but Bulk specific gravity of WMA-E is $2.45 \%$ greater than WMA-R. In the case of these two mixes, WMA-E is preferred as denser mix.

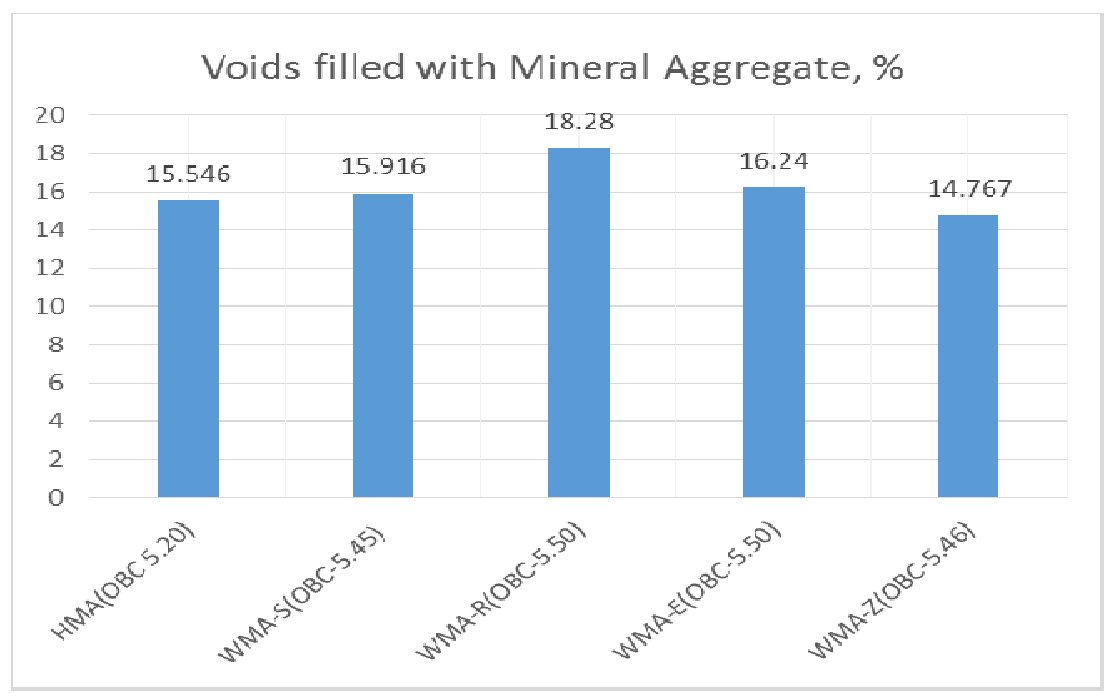

Fig 3.8 (c) Voids filled with Mineral Aggregate for OBC

The VMA values at OBC are represented in the figure 3.8(c). From the observation it was found that WMA-S with OBC $5.45 \%$ has the satisfactory value of VMA which is greater than minimum specified value as per MoRT\&H at the lesser binder content. In comparison of these two mixes WMA-R and WMA-E which are having the same OBC of 5.50\%, but the percentage of VMA of WMA-R is $12.56 \%$ higher than WMA-E, hence WMA-R is better among these two mixes. But from the overall observation, WMA-R is preferred because it has got the higher percentage of VMA. 


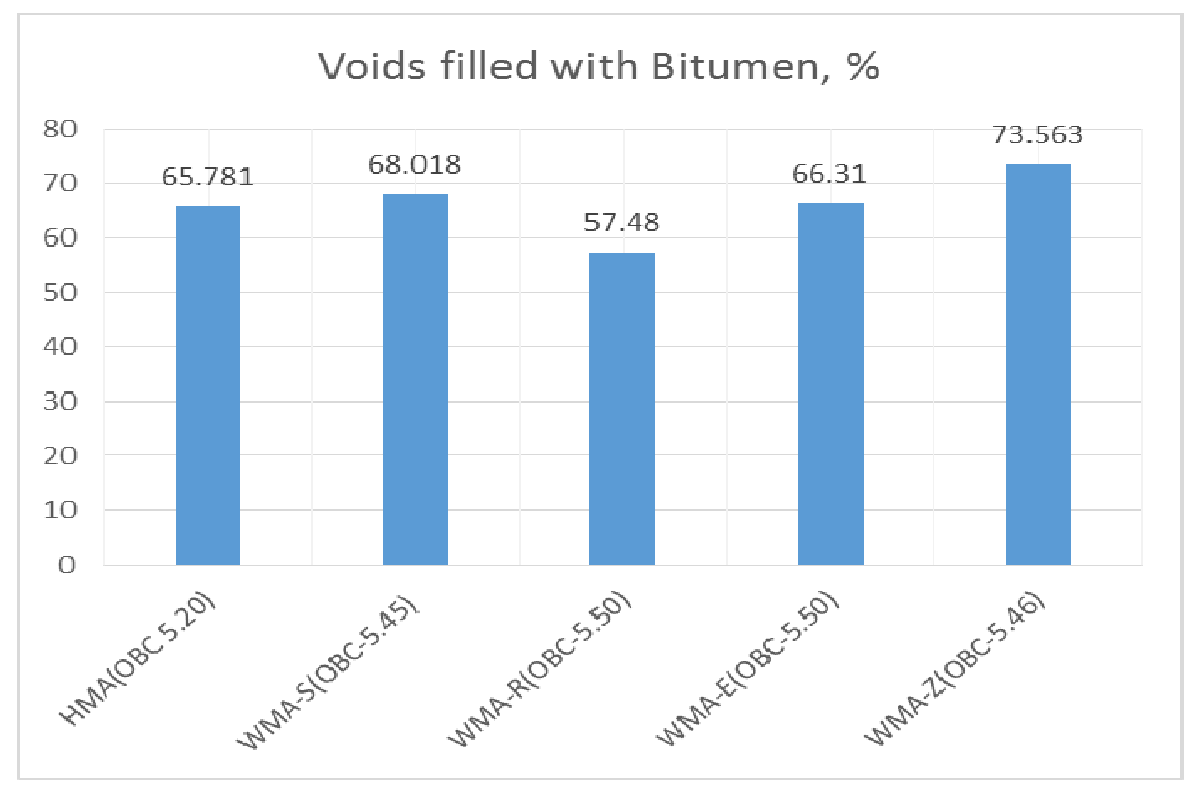

Fig 3.8 (d) Voids Filled with Bitumen for OBC

The percentages of Voids Filled with Bitumen at OBC are represented in the figure 3.8(d). From the observation of two mixes WMA-R and WMA-E, even though having the same OBC, the VFB percentage of WMA-E is 15.36\% higher than WMA-R due to the change in the additive which gives the better compaction. Hence WMA$\mathrm{E}$ is preferred among these two mixes. Considering the overall observation, WMA-Z is having higher VFB value among all the mixes hence it is highly preferred as it gives better compaction. Also WMA-R is having VFB percentage below the desired limit as per the specifications of MoRT\&H hence it is least preferred

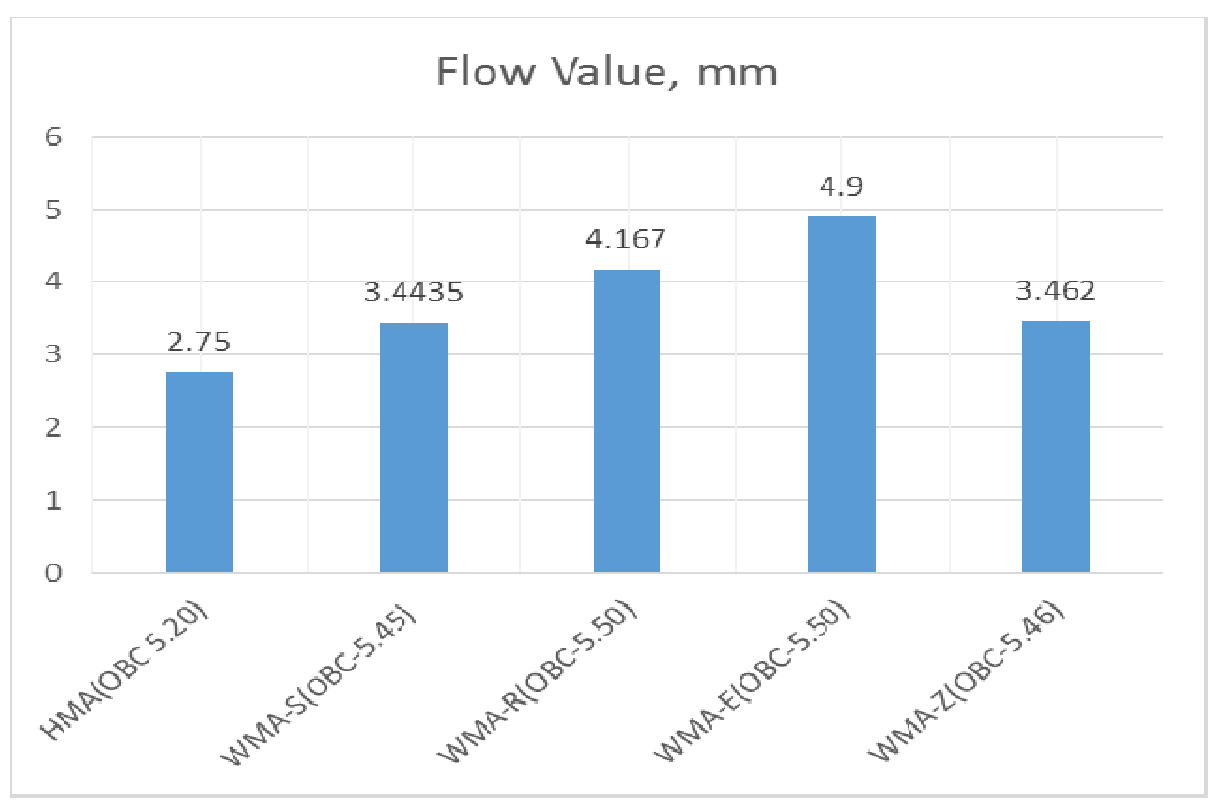

Fig 3.8 (e) Flow Value of OBC

The Flow value at OBC are represented in the figure 3.8(e). From the observation it was found that WMA-S with OBC $5.45 \%$ has the lower flow value. HMA is having the flow value lesser than the desired range as per MoRT\&H which results in difficulty while mixing. Considering the two mixes WMA-R and WMA-E which are having the same OBC, the flow value of WMA-E is $17.59 \%$ greater than WMA-R. Here WMA-E is not preferred because increased flow value leads to segregation. From the overall observation WMA-S and WMA-Z are preferred as they are having the flow value which is within the desired limit as per MoRT\&H and also gives better property to the mix. 


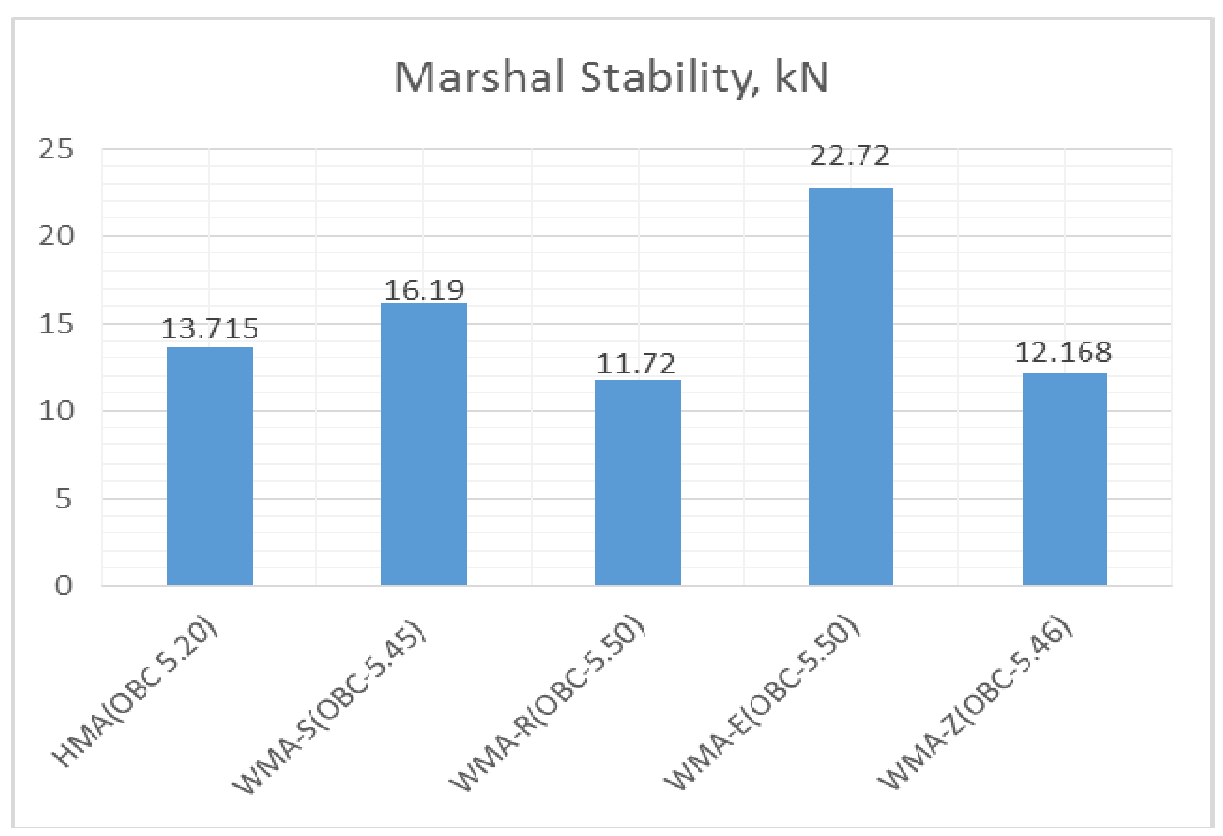

Fig 3.8(f) Marshal Stability of OBC

The Marshal Stability at OBC are represented in the figure 3.8(f). While comparing the two mixes WMA-R and WMA-E which are having same OBC, but the marshal stability of WMA-E is 93.85\% higher than WMA-R due to the unique properties of the additive. In this case WMA-E is preferred as it has the higher stability. Even from the overall observation WMA-E gives the higher stability compared with all other mixes hence it is highly preferred whereas WMA-R is least preferred as it has got the least marshall stability among all the mixes.

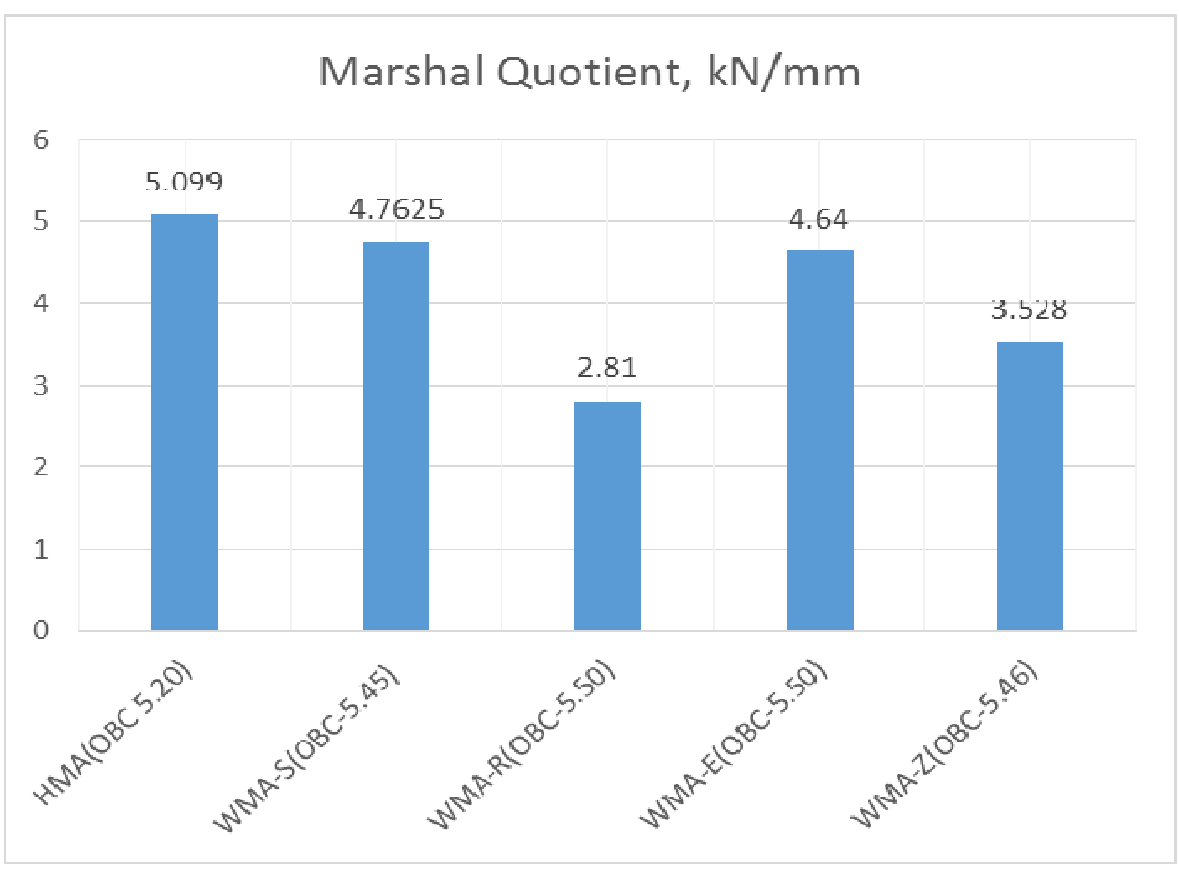

Fig 3.8 (g) Marshal Quotient of OBC

The Marshal Quotient at OBC are represented in the figure 3.8(g). It was found that WMA-Z with OBC 5.46\% has the Marshal Quotient value within the specified limit as per MoRT\&H at the lesser bitumen content. Considering the two mixes WMA-R and WMA-E, the marshal quotient of WMA-E is $65.12 \%$ higher than WMA-R even though they are having same OBC of 5.50\%. 


\section{CONCLUSION}

As per the basis of analysis of result obtained from the present investigation, the OBC of HMA was found $5.20 \%$ and for WMA-S is $5.45 \%$, for WMA-R and WMA-E is $5.50 \%$ and for WMA-Z is $5.46 \%$. The Flow value plays an important role in homogeneous mix but segregation occurs due to the presence of additives. HMA shows the lower flow value of $2.75 \mathrm{~mm}$ which results in homogeneous mix. But among the WMA mixes, WMA-S with flow value $3.45 \mathrm{~mm}$ at $\mathrm{OBC} 5.45 \%$ gives the reasonable flow value. Among overall mixes WMA-E gives the highest stability hence it is preferred as a replacement to HMA mix. By VMA, VFB, Bulk specific gravity, Marshal Quotient, air voids percent, Flow value and Marshal Stability of the WMA-S at OBC $5.45 \%$ is suggested at an economical dosage as a replacement for HMA mix.

\section{ACKNOWLEDGMENT}

We owe our profound gratitude to Alva's Institute of Engineering and Technology, for supporting and encouraging us throughout.We thank Manisha Construction, Aurangabadfor providing additive for our project work. Finally we express our sincere gratitude for the inspiration, enthusiasm and help given by my parents and friends

\section{REFERENCES}

[1] AkzoNobel, NYSDOT WMA Technology Approval, SundaramLogaraj

[2] Amirhamza M. Chariwala, Shivam S. Patel, Mursalin M. Shaikh and Sagar A. Tailor, (2016). "A Study on Warm Mix Asphalt Technology on Bituminous Mixes using Rediset”.IOSR Journal of Mechanical and Civil Engineering, 13(4), 15-25.

[3] Behnam Kheradmand, RatnasamyMuniandy, Law Teik Hua, Robiah Bt. Yunus and Abbas Solouki, (2013). "An overview of the emerging warm mix asphalt technology”.International Journal of Pavement Engineering,15(1), 79-94.

[4] Hurley, G. C., and Prowell, B. D. (2005a). “Evaluation of Aspha-min zeolite for use in warm mix asphalt.”NCATRep.05-04, National Center for Asphalt Technology, Auburn Univ., Auburn, AL.

[5] IS 1201-1220-1978,"Methods for testing Tar and bituminous materials"

[6] IS 2786 ( part I to IV) -1963 "Methods for testing Aggregate"

[7] John Shaw , 2007, “TWG -Warm Mix Asphalt - Sasol”

[8] Km. Monu, Preeti Banger, A.K Duggal, (2015). “A review paper on warm mix asphalt technologies”.International Research Journal of Engineering and Technology, 2(5), 378-381.

[9] Manjunath S Sharanappanavar, (2016) "Study on Behaviour of Warm Mix Asphalt Using Zycotherm". International Journal of Science and Research, 5(10), 851-855.

[10] Mohamed. S. Ouf, Abdelzaher E. A. Mostafa, AmroEloufie, (2015) "Producing of Warm Mix Asphalt Using Sasobit”. International Journal of Scientific \& Engineering Research, 6(12), 509-517.

[11] MoRT\&H (2009), "Section 500 Base and Surface Course”

[12] Nathan Bower, Haifang Wen, Kim Willoughby, Jim Weston, Joe Devol, (2012) “Evaluation of the Performance of Warm Mix Asphalt in Washington State.”

[13] Prof. Amitkumar A. Patel and Tushar A. Kansagra, (2015). "Experimental Investigation on Warm Mix using Zycotherm as a Chemical Additive with PMB 40 in Mix Design”. International Journal for Scientific Research \& Development, 2(12), 859-860.

[14] RajanChoudhary and Ashok Julaganti, (2014). "Warm mix asphalt:Paves way for energy saving”.Recent Research in Science and Technology, 6(1), 227-230.

[15] Renugadevi. A, (2014). “Evaluation of Marshall Properties of Warm Mix Asphalt using Sasobit”.International Journal of Engineering Sciences \& Research Technology, 3(12), Pg 421-428.

[16] Wekumbura, C., Stastna, J., and Zanzotto, L. (2007). “Destruction and recovery of internal structure in polymer-modified asphalts.” J. Mater. Civ. Eng., 19(3), 227-232.

[17] Zhen Leng, A.M.ASCE, AngeliGamez, Imad L. Al-Qadi and Dist.M.ASCE, (2014). "Mechanical Property Characterization of WarmMix Asphalt Prepared with Chemical Additives”. Journal of Material Civil Engineering, 26(2), 304-311. 